\title{
Coupled Electrochemical Processes for Removing Dye from Soil and Water
}

\author{
Suelya da Silva Mendonça de Paiva, ${ }^{1}$ Iasmin Bezerra da Silva, ${ }^{1}$ \\ Elaine Cristina Martins de Moura Santos, ${ }^{2}$ Ingrid Medeiros Veras Rocha, ${ }^{1}$ \\ Carlos Alberto Martínez-Huitle, $\mathbb{1}^{2,3}$ and Elisama Vieira dos Santos $\mathbb{1}^{1, z}$ \\ ${ }^{I}$ School of Science and Technology, Federal University of Rio Grande do Norte, 59078-970 Natal, Brazil \\ ${ }^{2}$ Institute of Chemistry, Federal University of Rio Grande do Norte, 59078-970 Natal, Brazil \\ ${ }^{3}$ Unesp, National Institute for Alternative Technologies of Detection, Toxicological Evaluation and Removal of \\ Micropollutants and Radioactives (INCT-DATREM), Institute of Chemistry, 14800-900 Araraquara (SP), Brazil
}

\begin{abstract}
In this work, a coupled remediation approach is studied by using electrochemical technologies (electrokinetic remediation (ER) and after that, BDD-electrolysis) to remove an azo dye from soil and after that, the elimination of dye from generated effluents was also attained. ER experiments were carried out using graphite electrodes, by applying $1 \mathrm{~V} \mathrm{~cm}^{-1}$ for $14 \mathrm{~d}$, investigating the use of solutions containing with $0.05 \mathrm{M}$ of $\mathrm{Na}_{2} \mathrm{SO}_{4}$ and $0.05 \mathrm{M}$ of sodium dodecyl sulfate (SDS) in the anodic and cathodic reservoirs, respectively. The results clearly indicated that SDS favors the elimination of organic pollutant from the soil, achieving $65 \%$. However, the removal efficiency is increased (89\%) when sodium sulfate solution was used as supporting electrolyte. The transport of organic compound in the soil from the cathode to anode reservoir was due to the electromigration phenomenon. Toxicity tests were performed to evaluate the reuse of the soil after remediation, then, the germination of sunflower seeds was carried out, achieving significant percentage of germination in central soil positions $(65 \%$ and $92 \%)$. Finally, the effluent generated by ER was treated with BDD-electrolysis, obtaining complete discoloration after $80 \mathrm{~min}$ and a quasi-complete elimination of organic matter (more than 95\%) after 120 min due to the contribution of persulfate $\left(\mathrm{S}_{2} \mathrm{O}_{8}{ }^{2-}\right)$ electrochemically generated at BDD anode.

(C) 2018 The Electrochemical Society. [DOI: 10.1149/2.0391809jes]
\end{abstract}

Manuscript submitted March 21, 2018; revised manuscript received May 14, 2018. Published June 1, 2018.

The intensification of industrial activities has caused significant environmental pollution, with negative consequences for water, atmosphere, and soil. ${ }^{1}$ Higher amounts of dye are annually produced and these are extensively used in different branches of the industry (textile dyeing/finishing, food, paper, cosmetic and so on). ${ }^{2}$ In the case of textile industry, a significant amount of dye-effluents are produced. ${ }^{3}$ Moreover, around 280,000 tons of textile dyes are currently discharged in the aquatic environmental. ${ }^{4}$ Additionally, the pollution of soil through dyes accumulation is also feasible when the aquatic eco-system is not treated or when the percolation of contaminated surface water to the subsurface strata occurs, leaching of wastes from landfills or direct discharge of textile industrial wastes to the soil. ${ }^{5}$ Therefore, different treatment technologies have been used to depollute wastewaters such as adsorption, coagulation, bioremediation, advanced oxidation process and electrochemical approaches. ${ }^{6-8}$ Meanwhile, in the case of soil decontamination, a limited number of reports about dye removal from contaminated soils were published in the literature..$^{9-12}$ In this context, more studies must be performed to depollute soil contaminated with dyes by applying other remediation technologies.

In the last decades, electrokinetic remediation (ER) has received great attention for removing organic and inorganic compounds in contaminated soils. It involves a low direct current or a low potential gradient to electrodes inserted in the low permeable soils; promoting different complex mechanisms (electrolysis, electro-osmosis, electromigration, and electrophoresis) in order to favor the transport of pollutants across the soil. ${ }^{13,14}$ During the ER treatment, the charged contaminants are transported toward one of the electrode chambers where it will be concentrated. Based on the existing literature, ${ }^{15}$ the efficacy of ER depends on the operating conditions, but it can be improved by adding surfactants and/or salts in the solutions used as supporting electrolytes. ${ }^{12,16-18}$ In this frame, this work aims to investigate, for the first time, the applicability of ER to eliminate azo dye, methyl orange (MO) as model the pollutant, from real soil sample by using sodium sulfate and SDS, as mobility promoters. After that, the toxicity of residual organic compounds was evaluated in the soil after treatment by the sunflowers (Helianthus Annuus) survival capacity ${ }^{19}$ in order to propose the safe reuse of the soil. Finally, electrochemical oxidation process with boron-doped diamond (BDD) anode was used to treat the effluents generated by ER approach, evaluating COD decay, color removal and $\mathrm{S}_{2} \mathrm{O}_{8}{ }^{2-}$ production.

\section{Experimental}

Soil spiking procedure.-The soil was collected in Natal (Norwest Brazilian region). The main physical and chemical properties were measured according to standard methods and summarized in Table I. ${ }^{20}$ The soil was air-dried, sieved $(2 \mathrm{~mm})$ to remove stones and large particles to obtain a saturated sample containing an uniform distribution of contaminant. According to the international soil science classification, composition and particle size distribution corresponds to red latosol soil. ${ }^{21}$ The soil was contaminated with MO by dissolving a well-known amount in water and thoroughly mixed with a measured quantity of soil to get a final concentration of $500 \mathrm{mg} \mathrm{kg}^{-1}$. The spiked soil specimen was dried for three days in a fume hood until complete drying. To ensure uniform distribution of the dye, it was mixed once a day during the drying process. For each test, approximately $4000 \mathrm{~g}$ of dry soil was manually compacted and separated from the electrode compartments by a $0.5 \mathrm{~mm}$ nylon mesh.

Cell setup configuration.-The remediation tests were carried out in a bench setup, which was constructed from transparent methacrylate divided into five compartments, more information is reported elsewhere. ${ }^{22}$ The graphite electrodes were connected to a direct current (DC) electric power source (MINIPA-3305 M) by applying $1.0 \mathrm{~V} \mathrm{~cm}^{-1}$ during $14 \mathrm{~d}$. The central compartment was filled with the contaminated

Table I. Physical and chemical characteristics of studied soil.

$\begin{array}{ll}\mathrm{Si} & 59.65 \% \\ \mathrm{Ca} & 15.70 \% \\ \mathrm{Al} & 12.34 \% \\ \mathrm{Fe} & 5.54 \% \\ \mathrm{~K} & 3.11 \% \\ \mathrm{Sand} & 65 \% \\ \mathrm{Silt} & 17 \% \\ \text { Clay } & 18 \% \\ \text { Organic matter }(\%) & 3.75 \\ \text { Initial pH of soil } & 6.8 \\ \text { Electric conductivity }\left(\mu \mathrm{S} \mathrm{cm}^{-1}\right) & 12.81\end{array}$




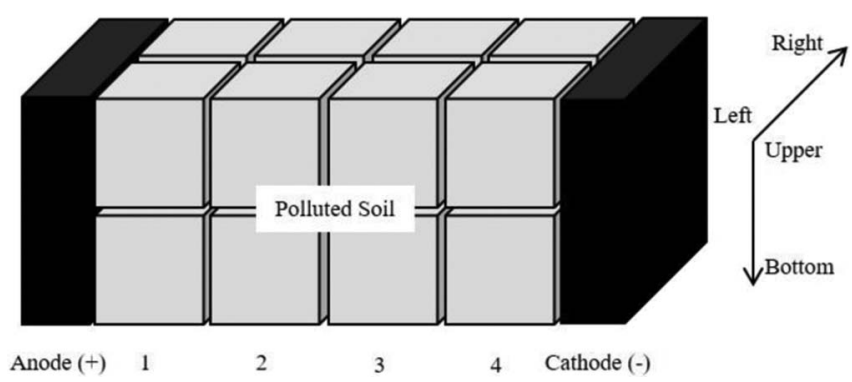

Figure 1. Experimental scheme used to study the ER process and soilsampling portions distribution for post mortem analysis.

soil. Acronyms were used to express the approaches investigated with a subscript abbreviation, indicating the anolyte/catholyte solutions used in the reservoirs, as follow: Exp tap water/SDS and $E x p_{\mathrm{Na}_{2} S O_{4} / S D S}$. In the first case, anodic and cathodic compartments were filled with tap water and $0.05 \mathrm{M}$ of sodium dodecyl sulfate (SDS), respectively. In the second case, the compartments were filled with $0.05 \mathrm{M} \mathrm{Na}_{2} \mathrm{SO}_{4}$ and $0.05 \mathrm{M} \mathrm{SDS}$. In the case of $\mathrm{Na}_{2} \mathrm{SO}_{4}$, it was used to promote the increase of soil conductivity and consequently, decreasing the treatment time and costs, as already reported in the existing literature. ${ }^{12}$ Electrical current, conductivity, $\mathrm{pH}$, SDS concentration, chemical oxygen demand (COD) and dye removal were monitored during the ER treatment as well as the electro-osmotic liquid volume transported from the cathode collector to the anodic reservoir as well as the germination of the plant. The soil sample was divided into sixteen portions after $14 \mathrm{~d}$ of treatment. Each soil-portion was manually homogenized, and representative samples were withdrawn for subsequent analyses (see Figure 1).

Toxicity tests.-Helianthus Annuus (sunflowers) were selected as toxicity vegetal-factor based on previous studies about survival capability in mixed contaminated soil with organic and inorganic compounds. ${ }^{23}$ The sunflower seeds were supplied by EMBRAPA, Brazil. After the ER experiments, the soil sample was divided in 16 soil-portions for post-mortem analysis (Figure 1), but only the superior soil-portions were used for toxicity tests. To do this, left and right portions, from the main four sections, were mixed to obtain four soil samples and subsequently, these were preserved (denominated as 1 , 2, 3 and 4 positions). From each one of the samples generated, $40 \mathrm{~g}$ of the soil was used for toxicity tests. The soil samples were capped and incubated in the dark at $25^{\circ} \mathrm{C}$ for 7 days.

The germination index (GI) was calculated by counting the number of the germinated seeds and the average root length observed in each sample compared to control treatments. ${ }^{24-26}$ The results were expressed according to the following equations:

$$
\begin{aligned}
& \text { Relative seed germination }(\%) \\
& \quad=\frac{\text { Number of seeds germinated in sample }}{\text { Number of seeds germinated in control }} \times 100
\end{aligned}
$$

$$
\begin{aligned}
& \text { Relative root elongation }(\%) \\
& \quad=\frac{\text { Mean root elongation in sample }}{\text { Mean root elongation in control }} \times 100
\end{aligned}
$$

$$
G I(\%)=\frac{\text { Seed germination }- \text { Root elongation }}{100 \%} \times 100
$$

BDD-electrolysis.-During the soil remediation, the contaminants present in the pore fluid and desorbed from the soil surface, will be transported toward the electrodes reservoirs, and consequently, residual effluent is generated. BDD-electrolysis was carried out at lab scale with an open, cylindrical and undivided two-electrode cell of $500 \mathrm{~cm}^{3}$ of capacity. The effluent was kept under constant agitation by using a magnetic stirrer. The anode was a BDD electrode $\left(32 \mathrm{~cm}^{2}\right)$, while a titanium plate was used as cathode $\left(32 \mathrm{~cm}^{2}\right) \cdot{ }^{27,28}$ All the trials were performed at applied current density (j) of $60 \mathrm{~mA} \mathrm{~cm}^{-2}$. Before the electrolysis, BDD anode was polarized in $100 \mathrm{~cm}^{3}$ of $0.05 \mathrm{M}$ $\mathrm{Na}_{2} \mathrm{SO}_{4}$ at $60 \mathrm{~mA} \mathrm{~cm}{ }^{-2}$ for $60 \mathrm{~min}$ to remove the impurities. ${ }^{27}$

Analytical methods.-For the determination of $\mathrm{pH}$ and conductivity in soil samples, the standard method EPA 9045C was used. ${ }^{29}$ This method consists of the mixture of $10 \mathrm{~g}$ of dry soil with $25 \mathrm{~mL}$ of distilled water and magnetically agitated for $10 \mathrm{~min}$. After sedimentation, the aqueous supernatant phase was prepared to analysis. All the samples (pre and post mortem) were filtered with $0.45 \mu \mathrm{m}$ nylon filters from Whatman before their analysis. COD was determined in the liquid and soil samples. Soil samples $(5 \mathrm{~g})$ were mixed with $15 \mathrm{~mL}$ of water and agitated vigorously in a vortex agitator for $10 \mathrm{~min}$, achieving the extraction of the dye. Samples were withdrawn from the organic supernatant phase and these were analyzed. For BDD-electrolysis, aliquots of 200 microliters were analyzed by using in situ chemical oxidation (ISCO) method via the reaction between the persulfate formed and $\mathrm{I}^{-}$ions, after that, the colored solution was evaluated from 190 to $600 \mathrm{~nm}$ with a Shimadzu spectrophotometer model 1800 and consequently, the $\mathrm{S}_{2} \mathrm{O}_{8}{ }^{2-}$ concentration was determined. ${ }^{30}$ SDS concentration was evaluated by colorimetric method. ${ }^{31}$ Regarding the point of zero charge (ZPC) of soils was determined by electrophoretic mobility. ${ }^{32}$ Soil samples of $1.5 \mathrm{~g}$ were suspended in $15 \mathrm{~mL}$ of 0.1 , 0.01 , and $0.001 \mathrm{M} \mathrm{KCl}$ and the $\mathrm{pH}$ adjusted between 3 and 8 . The suspensions were kept at room temperature $\left(26 \pm 1^{\circ} \mathrm{C}^{\circ}\right)$ in capped plastic vials of $50 \mathrm{~mL}$ and shaken twice daily over a $3 \mathrm{~d}$ period. After this time, the $\mathrm{pH}$ values of the supernatants were registered. z-potential measurements were performed by using Zetasizer Nano analyzer (Malvern).

\section{Results and Discussion}

Elimination of dye from soil.-Figure 2 shows the transport of the organic matter (in terms of COD removal ( $a$ and b) and SDS concentration (c and d)) from the soil to anodic reservoirs during the ER tests by applying $1 \mathrm{~V} \mathrm{~cm}^{-1}$ for $14 \mathrm{~d}$. Due to the elimination of $\mathrm{MO}$, the solutions in the anode reservoirs become colored, after soil remediation; then, COD was measured in the anodic and cathodic reservoirs. As it can be observed in Figure $2 a$ and Figure $2 b$, a significant increase on the COD in the anodic reservoir was achieved, while COD decays in the cathodic compartment. This behavior clearly indicates that the organic matter in the soil (the azo dye) as well as in the cathodic compartment (the surfactant), respectively, was transported to the anodic reservoir. In both experiments, the use of surfactant favored an increase on the solubility and mobility of organic matter during ER due to the formation of micelles, assisting the extraction of pollutants from the soil by electromigration phenomenon. In fact, the concentration of SDS effectively decreased in the cathodic reservoir in both experiments (see, Figures $2 \mathrm{c}$ and $2 \mathrm{~d}$ ). However, the decontamination efficiency increased when sulfate was used ( $\left.\operatorname{Exp}_{\mathrm{Na}_{2} S \mathrm{SO}_{4} / S D S}\right)$ as electrolyte because the organic matter transported to anodic section increased. Interestedly, the use of sodium sulfate in the anolyte contributed to reduce the resistivity of the soil, increasing the electric conductivity and consequently, this effect favored the dye-desorption from the soil particles. Simultaneously, $\mathrm{Na}^{+}$and $\mathrm{SO}_{4}{ }^{2-}$ ions are transported through the soil from one reservoir to the other due to the effect of the electric field. ${ }^{12}$ Certainly, the changes in the $\mathrm{pH}$ conditions also contribute to the transport of organic and inorganic compounds because of the electrolytic reactions that occur on the electrode surfaces. In fact, $\mathrm{pH}$ variations promote acidic and alkaline fronts from side to side in the soil toward the opposite electrode due to the generation of hydrogen and hydroxide species, Eqs. 4 and $5 .^{33}$

Anode (Oxidation):

$$
4 \mathrm{H}_{2} \mathrm{O}_{(\mathrm{l})} \rightarrow 4 \mathrm{e}+4 \mathrm{H}^{+}{ }_{(\text {aq })}+\mathrm{O}_{2 \text { (gas) }} \quad \mathrm{E}^{\circ}=-1.229 \mathrm{~V}
$$



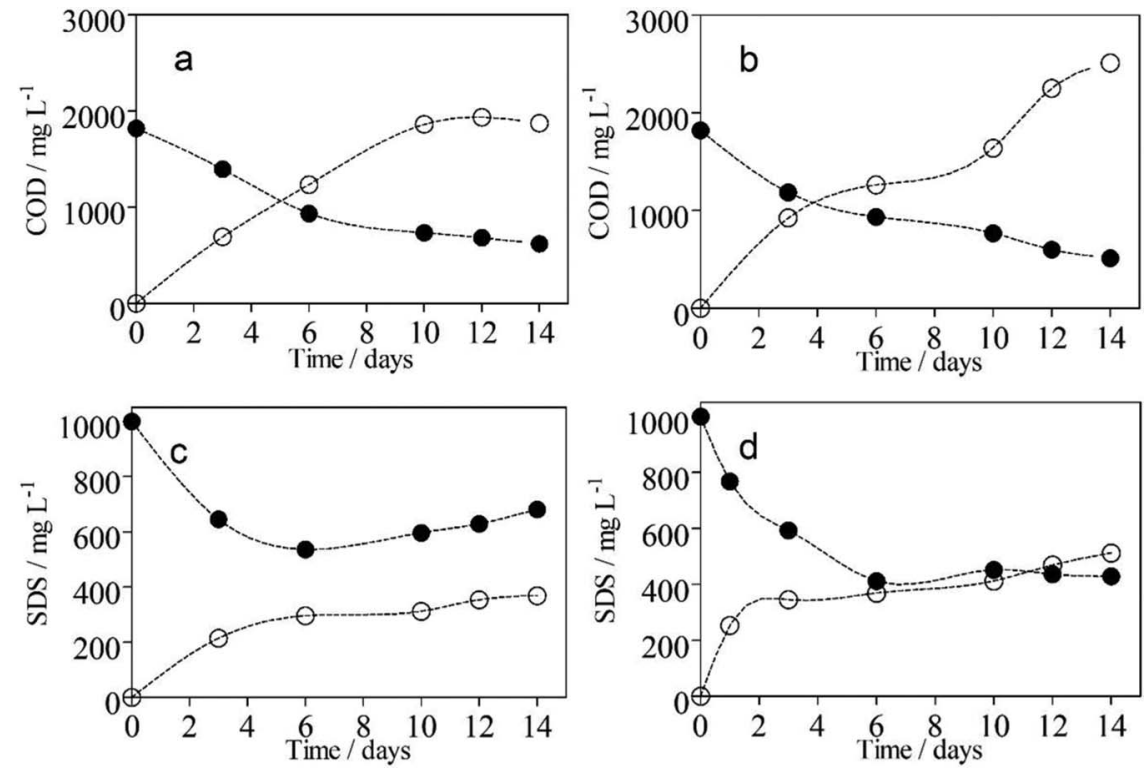

Figure 2. Changes in the anodic (o) and cathodic (reservoirs, for COD and SDS, during the remediation of the soil by ER by applying $1 \mathrm{~V} \mathrm{~cm}^{-1}$ for $14 \mathrm{~d}$. Experimental conditions: Exptap water/SDS (a and c) and

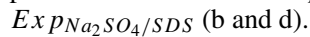

\section{Cathode (Reduction):}

$$
4 \mathrm{H}_{2} \mathrm{O}_{(\mathrm{l})}+4 \mathrm{e} \rightarrow 2 \mathrm{H}_{2(\mathrm{gas})}+4 \mathrm{OH}^{-}{ }_{(\mathrm{aq})} \quad \mathrm{E}^{\circ}=-0.828 \mathrm{~V}
$$

Figure 3 shows the $\mathrm{pH}$ and conductivity variations during the ER of soil polluted with MO. Results showed that the $\mathrm{pH}$ increased at the cathodic reservoir (ranging from 9.60 to 12.04), while a slight decrease in the anodic compartment was registered (from 3.07 to 4.60). This $\mathrm{pH}$ effect provoked significant variations in the conductivity due to the mobility of the ionic species from the soil as well as from the electrolyte solutions to different directions (Figs. 3a and 3b). These figures ( $\mathrm{pH}$ and conductivity changes) can also explain the behavior for the organic matter distribution observed during $14 \mathrm{~d}$ of treatment.
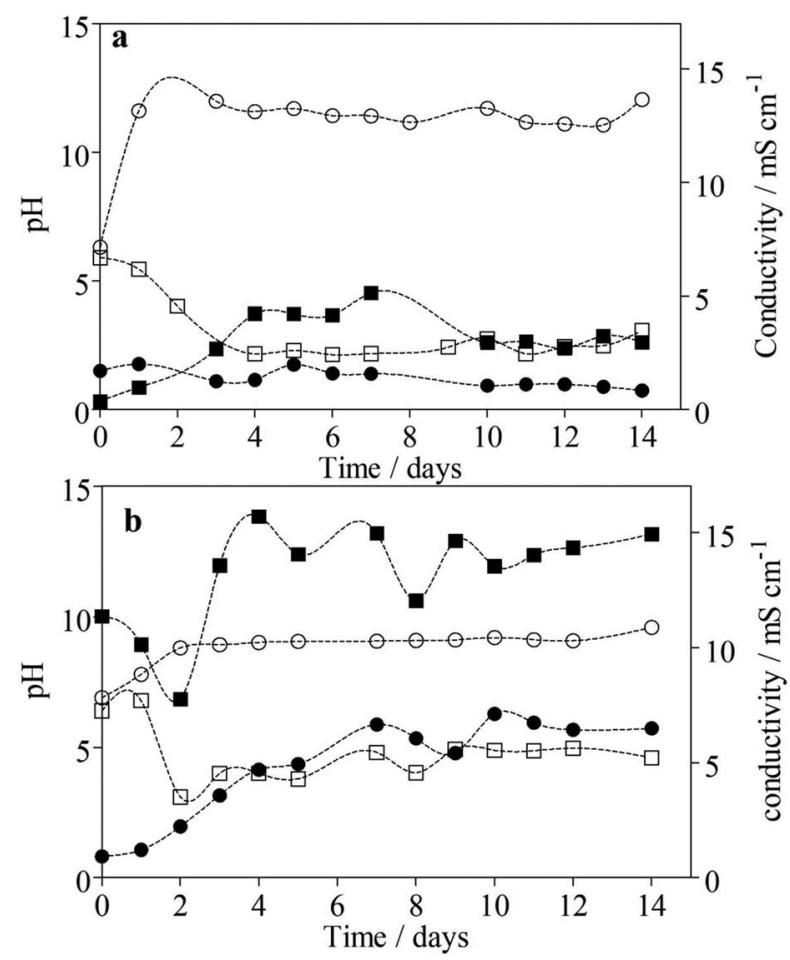

Figure 3. Changes in the $\mathrm{pH}$ (empty symbols) and conductivity (full symbols), for anodic ( $\square$ ) and cathodic ( $)$ reservoirs, during ER process: (a) Exptap water/SDS and (b) Exp $\mathrm{Na}_{2} \mathrm{SO}_{4} / \mathrm{SDS}$.
At low $\mathrm{pH}$ values, the micelles formed between MO and SDS are transported by electromigration to anodic regions from the soil due to the solubility in the acidic front, consequently, favoring an increase on the COD at the anodic reservoir (Figs. $2 a$ and $2 b$ ). In fact, negative charged-micelles are formed, which have electrostatic affinity for the acidic front. Meanwhile, the transport of $\mathrm{Na}^{+}$and $\mathrm{SO}_{4}{ }^{2-}$ ions also contributes to the electro-migration phenomenon when sulfate is used as supporting electrolyte, and important changes on the conductivity are observed (Figure 3b).

Electro-osmotic flow.-As expected, the electric gradient applied to the soil induces the movement of the pore fluid, which contains dissolved ionic and non-ionic species, toward the electrode reservoirs by electroosmosis. Figure 4 shows the equivalent changes of the electro-osmosis flux (EOF) by applying $1 \mathrm{~V} \mathrm{~cm}^{-1}$ for $14 \mathrm{~d}$, in both experiments. In the first day, the EOF was zero because the soil retained the water, and consequently, no EOF was achieved. However, an increase in the fluid accumulation from the cathodic reservoir was observed in both experiments, which indicated an efficient transference of the liquid. For Exp tap water/SDS, EOF increased from 0.70 to $2.15 \mathrm{~cm}^{3} \mathrm{~d}^{-1}$. Meanwhile, the most important increase of the EOF was

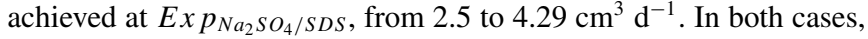
the direction of EOF depends on the zeta potential of soil particles. The soil has negative surface charge, approximately $30-80 \mathrm{mV}$ (zeta potential in the range); and, the water layer that is around the surface of soil particles can present high concentration of positive ions, related

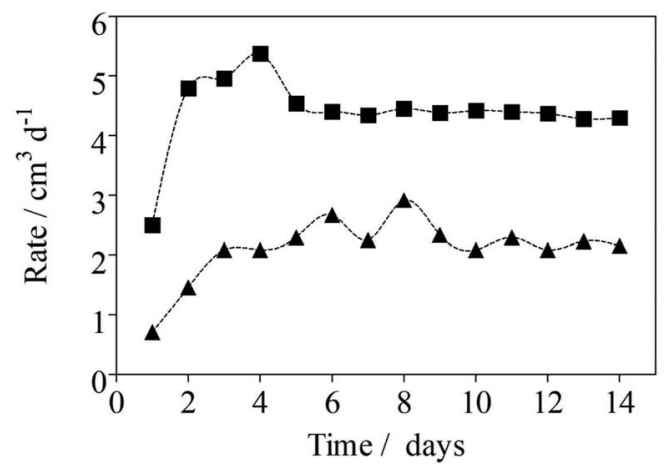

Figure 4. EOF changes, in cathodic reservoir, during the ER tests:

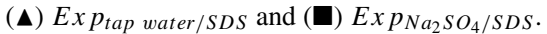


to the $\mathrm{pH}$ changes in the soil (as explained above). Consequently, the direction of water-mobilized by EOF was from anode to cathode. ${ }^{34}$

EOF is an important phenomenon that contributes to the transport process of the all components in the soil (organic and inorganic species that are in dissolved, suspended, emulsified, or similar forms) but it can contribute in their elimination depending on viscosity, soil-pH and charged particles. According to the Helmholtz-Smoluchowski theory, the EOF velocity $\left(v_{e o}\right)$ is directly proportional to the applied voltage gradient $\left(\mathrm{E}_{\mathrm{z}}\right)$, zeta potential $(\zeta)$ and dielectric constant $(\mathrm{D})$ of the fluid and it is inversely proportional to the fluid viscosity $(n):{ }^{35}$

$$
V_{e o}=-\frac{D \zeta}{\eta} E_{z}
$$

In this way, a lower fluid viscosity $\left(\approx 0.969 \times 10^{-6} \mathrm{~m}^{2} \mathrm{~s}^{-1}\right)$ contributes to increase the EOF $\left(\approx 2.01 \mathrm{~cm}^{3} \mathrm{~d}^{-1}\right) .{ }^{13}$ However, the soilparticles charge are affected by the $\mathrm{pH}$ variations induced in the soil, and thus, influencing effectively the EOF. Based on the measurements concerning the $\mathrm{pH}$ in the soil, values about 4.2 and 3.5 were registered in the anodic positions for Exp tap water/SDS and Exp $\mathrm{Na}_{2} \mathrm{SO}_{4} / S D S$ (positions 1 and 2), respectively. Conversely, in the cathodic positions (positions 3 and 4), the $\mathrm{pH}$ values increased up to 8.2 and 7.5 for Exp tap water/SDS and Exp $\mathrm{Na}_{2} \mathrm{SO}_{4} / S D S$, respectively.

Residual organic matter and efficiency of phenomena.-Figure 5 shows the concentration plot of organic matter, in terms of COD, at the end of the tests performed (commonly named, post mortem analysis). Results indicate that a significant elimination of the pollutants was attained after the application of the ER. However, the residual organic concentration was more significant in the anodic sections in the soil (positions 1 and 2 in Figures $5 \mathrm{a}$ and 5b), as a consequence of the partial elimination because the pollutants are transported from the soil toward anodic reservoir. Conversely, the elimination of pollutants was more efficiently attained at cathodic regions. For Exp tap water/SDS, COD values around $698 \mathrm{mg} \mathrm{kg}^{-1}$ were determined in the positions 3 and 4 (Fig. 5a). Meanwhile, $265 \mathrm{mg} \mathrm{kg}^{-1}$ of COD was measured in the same soil positions, for $\mathrm{Exp}_{\mathrm{Na}_{2} S \mathrm{SO}_{4} / S D S}$ after $14 \mathrm{~d}$ of treatment (Fig. 5b). Certainly, the efficacy of ER is enhanced by the presence of the $\mathrm{Na}^{+}$ and $\mathrm{SO}_{4}{ }^{2-}$ ions, which were included by using the $\mathrm{Na}_{2} \mathrm{SO}_{4}$ as sup-

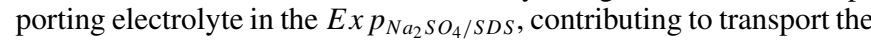
ionic species present in the pore fluid toward the opposite electrode by electromigration and electro-osmosis phenomena. From these results, the removal efficiencies (in terms of COD by the different mechanisms and the organic compounds remaining in the soil) were estimated and are shown in Figure 5c. For Exp tap water/SDS $51 \%$ of COD removal was achieved, while $79 \%$ was attained by adding sulfate in electrolyte

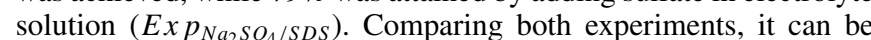
confirmed that, the addition of $\mathrm{Na}_{2} \mathrm{SO}_{4}$ contributed to increase the removal efficiency of organic compounds in the anodic reservoir by electromigration and electro-osmosis. Additionally, the fluid mobility, increased by using sulfate in solution, avoided the evaporation occurrence during the treatment of soil (Figure $5 \mathrm{c})\left(E x p_{N a_{2} S O_{4} / S D S} \approx 4 \mathrm{~cm}^{3}\right.$ $\mathrm{d}^{-1}$ ) when compared to the ER test without sulfate (Exp tap water/SDS $\left.\approx 10 \mathrm{~cm}^{3} \mathrm{~d}^{-1}\right)$. Analyzing Figure $5 \mathrm{c}$, we can observe that, $32 \%$ of organic compounds remained in the soil when sulfate was not added in the electrolyte $\left(E x p_{\text {tap water } / S D S}\right)$, but this percentage was decreased $(\approx 12 \%)$ after $14 \mathrm{~d}$ when the action of SDS and sulfate was combined

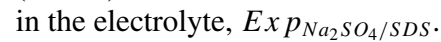

Toxicity.-ER contributed for removing organic compounds into the soil in both cases, but it is necessary to evaluate the toxicity of the soil after the treatment to assess the reuse-viability of the soil. To do this, vegetal-factor was investigated by the survival capability of sunflower seeds (\%GI). As can be observed in Figure 6, lower \%GI was attained in 1 and 4 positions of the soil; in both experiments. This behavior is related to the $\mathrm{pH}$ variations in the soil as well as the accumulation of the pollutants. In fact, acidic conditions were achieved at anodic soil-region (position 1) while high $\mathrm{pH}$ (around 8.2) was registered near to the cathodic section (position 4),
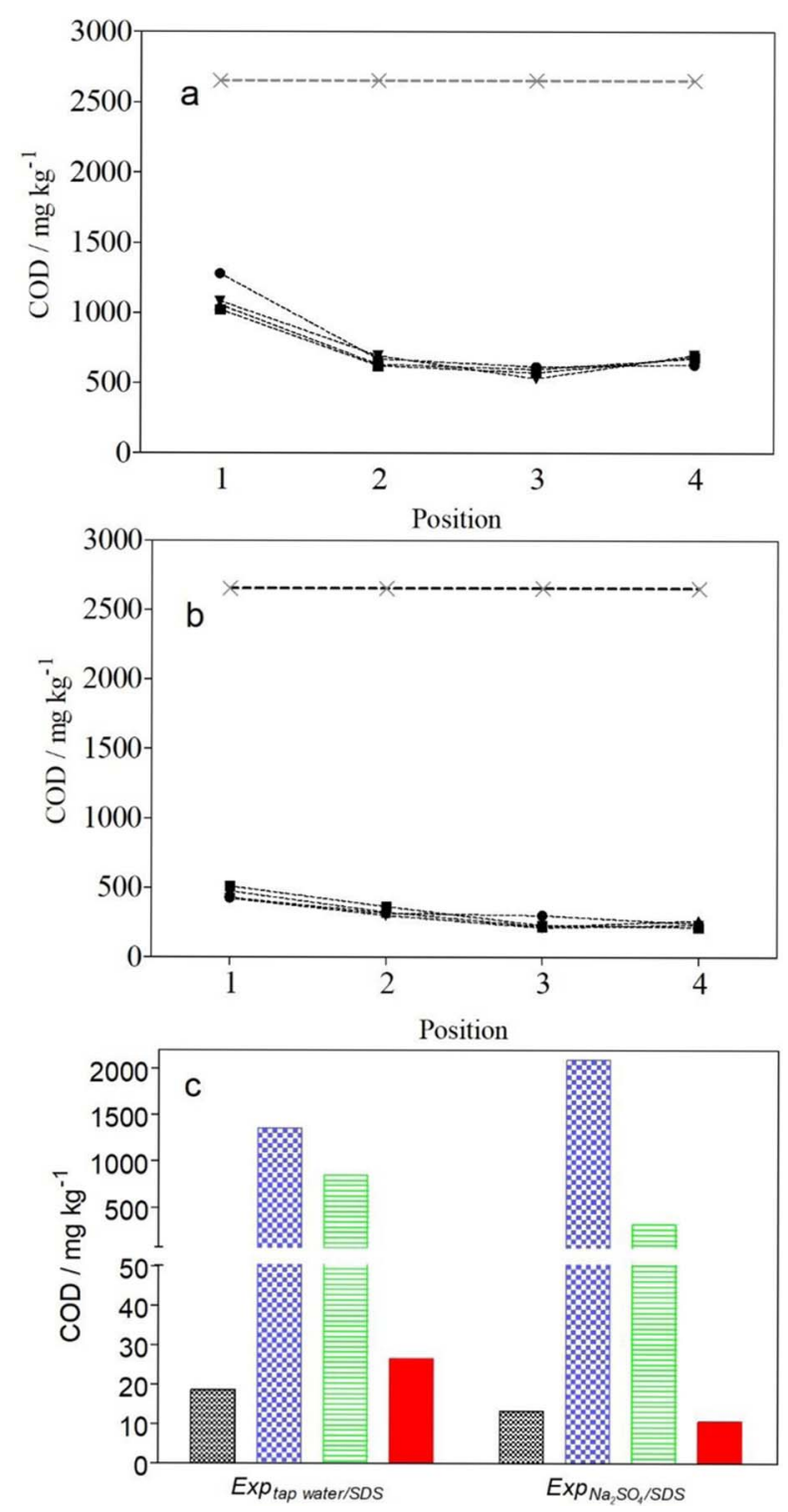

Figure 5. Residual COD concentration at different soil-region positions (anodic region 1 and cathodic region 4 , according the soil distribution scheme in Fig. 1: Upper right position ( $)$, upper left position ( $\mathbf{\square})$, bottom right position $(\boldsymbol{\Delta})$ and bottom left position $(\boldsymbol{\nabla})$. Initial COD concentration $(\mathrm{x}))$ after the ER treatment tests: (a) Exp tap water/SDS and (b) $E x p_{N_{2} a_{2} O_{4} / S D S}$. (c) Concentration of organic matter (in terms of COD) in cathodic reservoir solution (gray column), anodic compartment solution (blue column), COD measured in the soil after ER (green column) and fraction of the contaminants lost by evaporation phenomenon (red column).

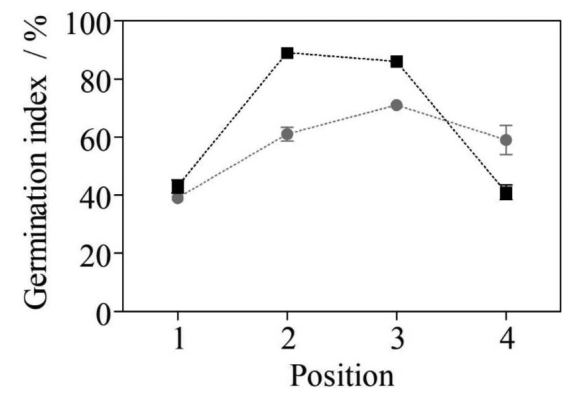

Figure 6. GI in the soil after treatment for (O) Exptap water/SDS and (ם)Exp $\mathrm{Na}_{2} \mathrm{SO}_{4} / \mathrm{SDS}$. The sample of soil treated for germination was $40 \mathrm{~g}$ during $7 \mathrm{~d}$ in incubation system at $25^{\circ} \mathrm{C}$. 

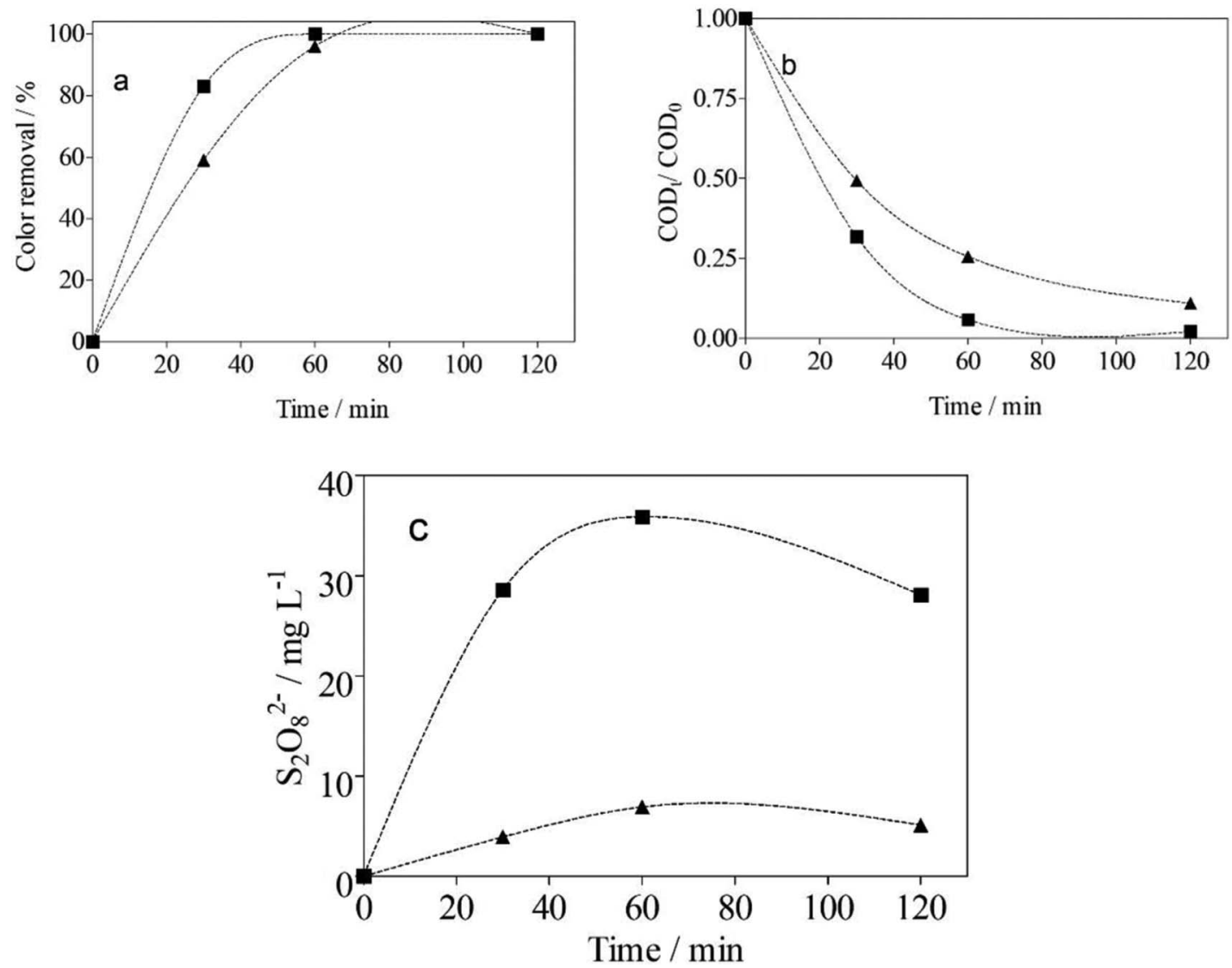

Figure 7. (a) color removal, (b) COD decay and (c) persulfate $\left(\mathrm{S}_{2} \mathrm{O}_{8}{ }^{2-}\right)$ concentration, as a function of time, during BDD-electrolysis by applying $60 \mathrm{~mA} \mathrm{~cm}^{-2}$ at $25^{\circ} \mathrm{C}$. (ム) effluent $t_{\text {Exp-1 }}$ and (ם) effluent $t_{\text {Exp-2 }}$.

which avoid the germination of the seeds. ${ }^{36}$ Additionally, a residual concentration of pollutants remained in the anodic soil-region, limiting the grown of the seeds. However, important \%GI was registered at central positions in the soil ( 2 and 3 position, see Figure 6 ), in both experiments. Approximately $60-70 \%$ of the seeds germinated at Exp tap water/SDS, while $92 \%$ was achieved when the soil

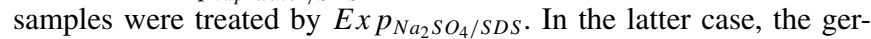
mination was significant because the $\mathrm{pH}$ values into the soil during $14 \mathrm{~d}$ were maintained between 4.2 and 7.5; and consequently, a homogeneous distribution of the nutrients for the sunflowers grown was attained. ${ }^{22}$

Bulk treatment of the effluents by BDD-electrolysis.-Once elucidated the feasibility of the ER to remove contaminants compounds in the soil, it is important to investigate the elimination of the organic compounds in the fluid generated. ${ }^{37}$ In this frame, the cathodic and anodic solutions were mixed between them, identifying the effluents as effluent $_{\mathrm{Exp}-1}$ and effleunt $\mathrm{Exp}-2_{\text {, }}$, which corresponds to $E x p_{\text {tap water } / S D S}$ and $\operatorname{Exp}_{\mathrm{Na}_{2} \mathrm{SO}_{4} / S D S}$ tests, respectively. The initial COD values were around 895 and $1476 \mathrm{mg} \mathrm{L}^{-1}$ for effluent $\mathrm{Exp}-1_{\text {and }}$ effleunt $\mathrm{Exp}_{-2}$, respectively. These liquid wastes were individually treated by BDDelectrolysis, applying $60 \mathrm{~mA} \mathrm{~cm}{ }^{-2}(1.92 \mathrm{~A})$ at $25^{\circ} \mathrm{C}$. As indicated above, the anodic solution was colored during ER, indicating the transference of the dye to the liquid. Then, color elimination was performed by anodic oxidation with BBD anodes, achieving a complete discoloration after $80 \mathrm{~min}$ of electrolysis, at both effluents (Figure 7a). The degradation of organic pollutants was achieved at both wastewaters due to the higher production of hydroxyl radicals on BDD surface, ${ }^{28}$ which oxidize the dissolved organic matter.

$$
\mathrm{H}_{2} \mathrm{O} \rightarrow \cdot \bullet \mathrm{OH}+\mathrm{e}+\mathrm{H}^{+}
$$

In the case of the effleunt ${ }_{\text {Exp-2 }}$, a rapid COD reduction was attained (Fig. 7b). This behavior is due to the use of $\mathrm{Na}_{2} \mathrm{SO}_{4}$ during ER approach, which also favored the electrogeneration of sulfate radical ion and persulfate on BDD surface. ${ }^{38}$ The oxidation of the $\mathrm{SO}_{4}{ }^{2-}$ ions occurs via the reaction with ${ }^{\bullet} \mathrm{OH}$ radicals at the beginning of electrolysis, ${ }^{38,39}$ forming $\mathrm{SO}_{4}{ }^{-\bullet}$ Reaction 8 , and persulfate (Reaction 9):

$$
\begin{array}{r}
\mathrm{BDD}\left({ }^{\bullet} \mathrm{OH}\right)+\mathrm{SO}_{4}{ }^{2-} \rightarrow \mathrm{BDD}\left(\mathrm{SO}_{4}{ }^{-\cdot}\right)+\mathrm{OH}^{-} \\
\mathrm{BDD}\left(\mathrm{SO}_{4}{ }^{-\bullet}\right)+\mathrm{SO}_{4}{ }^{2-} \rightarrow \mathrm{S}_{2} \mathrm{O}_{8}{ }^{2-}+\mathrm{e}-
\end{array}
$$

As already reported in previous work, ${ }^{38}$ the fragmentation of SDS, when it is used in the electrolyte, also contributes to generate persulfate electrochemically; and after that, this oxidant promotes the degradation of pollutants. For this reason, even when SDS, itself, as a surfactant, is polluting; then, its beneficial usage was already confirmed by its elimination when it is used. ${ }^{38}$ The production of persulfate was estimated during BDD-electrolysis at both effluents in order to understand the conditions where this oxidant can be produced in excess (the concentration determined corresponds to the oxidants that did not react with the organic pollutants). As can be observed in Figure $7 \mathrm{c}$, a lower $\mathrm{S}_{2} \mathrm{O}_{8}{ }^{2-}$ concentration was determined to the effluent $_{\text {Exp-1 }}$ at $60 \mathrm{~mA} \mathrm{~cm}^{-2}$, which is associated to the lower sulfate concentration in the soil because no sulfate was added in solution during ER. Conversely, an efficient electrogeneration of $\mathrm{S}_{2} \mathrm{O}_{8}{ }^{2-}$ was achieved when effleunt ${ }_{\text {Exp-2 }}$ was treated, allowing to measure the persulfate excess in the effluent, which indicates that enough persulfate is formed to degrade the organic matter. In this way, the association of electrochemical technologies can be a promising methodology to remove pollutants from soil, and after that, the effluents can be 

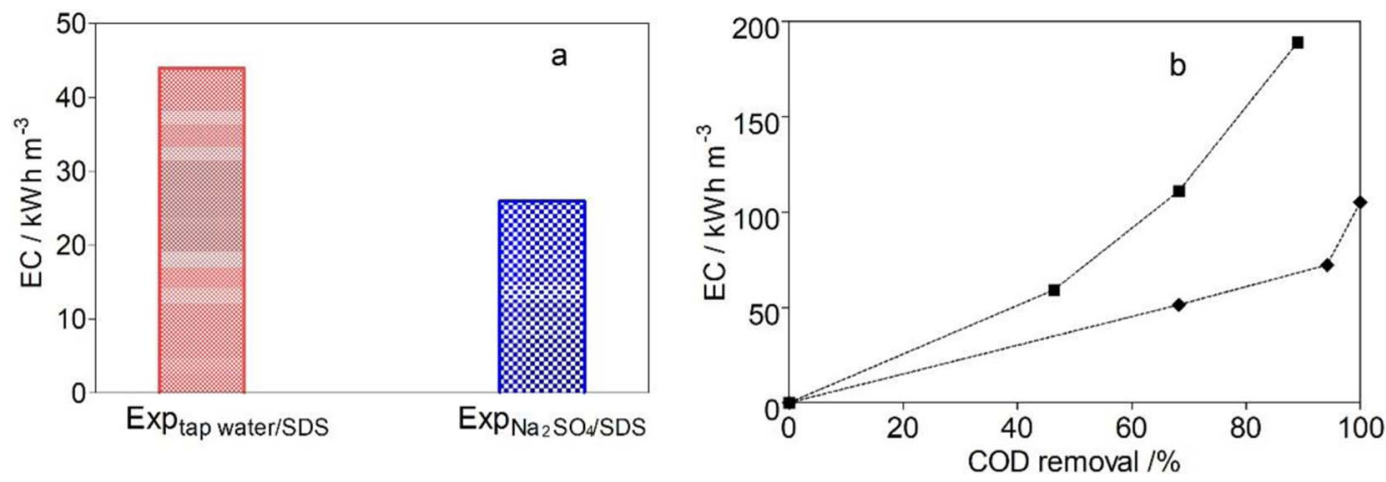

Figure 8. (a) EC for ER treatment by applying $1 \mathrm{~V} \mathrm{~cm}^{-1}$ and (b) EC, as function of COD removal, during the treatment of the effluents via BDD-electrolysis by applying $60 \mathrm{~mA} \mathrm{~cm}^{-2}$ at $25^{\circ} \mathrm{C}$. (ם) Exptap water $/ S D S$ and (\) $\operatorname{Exp}_{\mathrm{Na}_{2} S O_{4} / S D S}$.

efficiently treated by electrochemical oxidation technology based on BDD anodes.

Energy consumption.-Energy requirements (EC) were estimated, as a function of the percentage of COD removal, for ER and BDD-electrolysis (see Fig. 8) to evaluate the economic viability of an integrated-remediation approach. ER treatment (Fig. 8a), by applying $1 \mathrm{~V} \mathrm{~cm}^{-1}$ during $14 \mathrm{~d}$, consumed approximately 44 and $26 \mathrm{kWh} \mathrm{m}^{-3}$ for $E x p_{\text {tap water } / S D S}$ and $E x p_{\mathrm{Na}_{2} S O_{4} / S D S}$, respectively. As can be observed, higher EC was spent by $E x p_{\text {tap water/SDS }}$ with $75 \%$ of efficacy to remove organic pollutants. Conversely, higher elimination of organic pollutant (more than $90 \%$ in terms of COD) was achieved at $E x p_{\mathrm{Na}_{2} \mathrm{SO}_{4} / S D S}$ with lower EC (26 kWh $\mathrm{m}^{-3}$ ), when sulfate and SDS solutions were used as supporting electrolytes. Figure $8 \mathrm{~b}$ also shows the EC for BDD-electrolysis of effluent $_{\text {Exp-1 }}$ and effleunt $\mathrm{Exp}_{\text {-2 }}$ by applying $60 \mathrm{~mA} \mathrm{~cm}^{-2}$. As can be observed, lower EC for treating effleunt $\mathrm{Exp}_{\mathrm{E}-2}$ was registered due to the oxidative contribution of the persulfate to remove organic compounds in bulk. However, the EC requirements were higher due to the cell potentials registered during the treatment of each one of the effluents, $23.2 \mathrm{~V}$ and $15.1 \mathrm{~V}$ for effluent ${ }_{\text {Exp-1 }}$ and effluent $_{\text {Exp-2}}$, respectively.

\section{Conclusions}

From this work, the most important conclusions have been summarized as follows:

- ER is an efficient process for removing MO dye from the soil when SDS and sulfate were used. However, the characteristics of the decontamination strongly depend on the electrolyte used. Moreover, in both experiments occurs the transport of contaminant

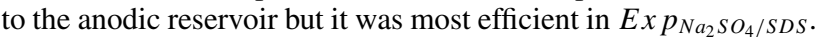
- After ER treatment, no significant \%GI of the sunflower seeds was achieved at the soil-region positions close to the anode and cathode. Conversely, \%GI was satisfactory in the central soil positions due to the depollution efficiency (lower concentration of the organic compounds remained) and the neutral $\mathrm{pH}$ conditions in the soil.

- Decontamination of effluents was achieved by BDD-electrolysis.

- SDS can be considered as an auxiliary reagent to depollute soils, for example, with a higher amount of oil or petroleum. After that, the dispersed systems can be electrochemically treated by BDDelectrolysis, as already confirmed in this work.

- Coupled electrochemical technologies, ER and BDD-electrolysis, can be considered as an efficient remediation approach for removing pollutants from soil and water.

\section{Acknowledgments}

Financial supports from National Council for Scientific and Technological Development $(\mathrm{CNPq}-430121 / 2016-4$ and $\mathrm{CNPq}$ 446846/2014-7), FAPESP (2014/50945-4) and L'ORÉAL - ABC UNESCO for Women in Science are gratefully acknowledged. The authors gratefully acknowledge the support given by NUPPRARUFRN.

\section{ORCID}

Carlos Alberto Martínez-Huitle (D)

https://orcid.org/0000-0002-6209-5426

Elisama Vieira dos Santos (1D https://orcid.org/0000-0003-2189-5694

\section{References}

1. OJEC D (2000) 60/EC of the European Parliament and of the Council of 23 October 2000 establishing a framework for Community action in the field of water policy. Official Journal of the European Communities, 22.

2. V. Khandegar and A. K. Saroha, J Environ manage., 128, 949 (2013).

3. E. Brillas and C. A. Martínez-Huitle, Appl Catal B Environ., 166-167, 603 (2015).

4. M. Sala and M. C. Gutiérrez-Bouzán, Int J Photoenergy., 1 (2012).

5. H. Shaylor, M. McBride, and E. Harrison, Cornell University, Department of Crop and Soil Sciences, Waste Management Institute., Ithaca, New York. Soil Contamination and Best Practices for Healthy Gardens. 1 (2009)

6. C. A. Martínez-Huitle, M. A. Rodrigo, I. Sirés, and O. Scialdone, Chem. Rev, 115, $13362(2015)$

7. R. Salazar, E. Brillas, and I. Sirés, Appl Catal B Environ., 115-116, 107 (2012).

8. P. A. Soares et al., Sep Purif Technol., 172, 450 (2017).

9. V. Jayanthy et al., Saudi J. Biol. Sci., 21, 324 (2014).

10. B. Rani et al., Braz. J. Microbiol., 45(3), 1055 (2014).

11. M. Pazos et al., Electrochim. Acta, 52, 3393 (2017).

12. S. Annamalai et al., Chemosphere, 117, 673 (2014).

13. K. R. Reddy, S and A. Chinthamreddy, Al Hamdan, Remed J., 11, 85 (2001).

14. C. Cameselle and K. R. Reddy, Electrochim Acta, 86, 10 (2012).

15. M. A. Rodrigo, N. Oturan, and M. A. Oturan, Chem. Rev., 114, 8720 (2014).

16. R. E. Saichek and K. R. Reddy, J. Environ. Eng. Sci., 4, 327 (2005).

17. E. Mena et al., J. Hazard. Mat., 283, 131 (2015).

18. E. V. Santos et al., J Hazard Mater., 322, 413 (2017).

19. P. J. Favas et al., Phytoremediation of soils contaminated with metals and metalloids at mining areas: potential of native flora, in: M. C. Hernandez-Soriano, (Eds) Environmental risk assessment of soil contamination., InTech, ISBN 978-953-51-1235-8, 2014.

20. M. R. Carter and E. G. Gregorich, Soil Sampling and Methods of Analysis, Taylor \& Francis Group, 2nd ed, Canada, 2006.

21. R. J. Law et al., Environ Int., 65, 147 (2014).

22. K. N. O. Silva et al., J. Electroanal. Chem., 816, 171 (2018).

23. R. A. Chirakkara, K. R. Reddy, and C. Cameselle, Electrochim Acta, 181, 179 (2015)

24. F. Zucconi et al., Biocycle., 22, 54 (1981).

25. C. S. O'connor et al., Environ. Monit. Assess., 84, 141 (2003).

26. D. P. Komilis, E. Karatzas, and C. P. Halvadakis, J. Environ. Manage., 74, 339 (2005).

27. C. A. Martínez-Huítle et al., J. Electroanal. Chem., 674, 103 (2012).

28. I. Sirés et al., Environ Sci Pollut. R., 21, 8336 (2014).

29. USEPA United States Environmental Protection Agency (1995) Method 9045 C: Soil and Waste $\mathrm{pH}$. Revision 3.

30. C. Liang et al., Chemosphere, 73, 1540 (2008). 
31. E. Jurado et al., Chemosphere, 65, 278 (2006).

32. C. Appel et al., Geoderma, 113, 77 (2003).

33. Y. B. Acar et al., J. Hazard. Mater, 40, 117 (1995).

34. Á. Yustres et al., Sep. Purif. Technol., 192, 196 (2018).

35. K. R. Reddy and C. Cameselle, Overview of electrochemical remediation technologies. Electrochemical Remediation Technologies for Polluted Soils, Sediments and Groundwater, John Wiley \& Sons, New Jersey, 1 (2009).
36. R. López-Vizcaíno et al., Electrochim. Acta, 225, 93 (2017)

37. E. B. S. Silva et al., Int. J. Electrochem. Sci., 12, 1247 (2017).

38. K. C. F. Araújo, J. P. P. Barreto, J. C. Cardozo, E. V. Santos, and D. M. Araújo, C. A., 2018. Environ. Chem. Lett., 16, 647 (2018).

39. J. H. B. Rocha, A. M. S. Solano, N. S. Fernandes, D. R. da Silva, J. M. Peralta-Hernandez, and C. A. Martínez-Huitle, Electrocatalysis, 3, 1 (2012). 